\title{
Tratamento cirúrgico das canaliculites crônicas: relato de nossa experiência em 7 casos
}

Surgical treatment of chronic canaliculitis: report of our experience in 7 cases

Roberto Murillo Limongi de Souza Carvalfio $^{1}$
José Byron V. D. Fernandes
$\begin{array}{lll}\text { Marcos } & \text { Volpini } & \\ \text { Suzana } & \text { Matayoshii } & \\ \text { Eurípedes } & \text { da Mota Moura } & \end{array}$

Trabalho realizado no Setor de Plástica Ocular do Hospital das Clínicas da Faculdade de Medicina da Universidade de São Paulo.

${ }^{1}$ Médico Assistente do Setor de Plástica Ocular do Centro de Referência em Oftalmologia do Hospital das Clínicas da Faculdade de Medicina da Universidade de Goiás, Pós-graduando nível Doutorado da Universidade de São Paulo.

${ }^{2}$ Médico Orientador do Setor de Plástica Ocular da Clínica Oftalmológica do Hospital das Clínicas da Faculdade de Medicina da Universidade de São Paulo.

${ }^{3}$ Médico responsável pelo Serviço de Plástica Ocular da

Santa Casa de Santo Amaro.

${ }^{4}$ Médica Assistente-Doutora da Clínica Oftalmológica do Hospital das Clínicas da Faculdade de Medicina da Universidade de São Paulo.

${ }^{5}$ Médico Assistente-Doutor e Chefe do Setor de Plástica Ocular da Clínica Oftalmológica do Hospital das Clínicas da Faculdade de Medicina da Universidade de São Paulo.

Endereco para correspondência: Av.Sucuri esq. C/ J81 n. 1500, Setor Jaó - Goiânia (GO) CEP 74673-100. E-mail: rmurillousp@hotmail.com

Nota Editorial: Pela análise deste trabalho e por sua anuência sobre a divulgação desta nota, agradecemos aos Drs. Ana Estela B. P. Sant'Anna e João Amaro Ferrari Silva.

\section{RESUMO}

Objetivo: Discutir as principais formas de tratamento existentes atualmente e relatar a nossa experiência com o tratamento cirúrgico das canaliculites crônicas. Métodos: Estudo retrospectivo com 7 casos atendidos na Clínica Oftalmológica do HC-FMUSP nos últimos 3 anos. Resultados: Todos os pacientes submetidos a tratamento cirúrgico tiveram cura completa dos sinais e sintomas. Conclusões: Devemos sempre lembrar da possibilidade de canaliculite em pacientes com queixa de epífora e secreção crônica no ponto lacrimal para que seja realizado o tratamento cirúrgico adequado.

Descritores: Infecções oculares bacterianas; Infecções por Actinomycetales; Doenças do aparelho lacrimal/cirurgia; Doença crônica

I N TRODUÇÃ O

A canaliculite crônica é uma doença incomum, de etiologia desconhecida, que deve ser considerada em todos o casos de conjuntivite crônica unilateral ${ }^{(1-2)}$. O quadro clínico geralmente se manifesta por epífora, irritação ocular e desconforto no canto medial, acompanhado por sinais de secreção ocular, eritema e espessamento da pálpebra medial, edema e refluxo de secreção no ponto lacrimal e às vezes saída de concreções pelo ponto (dacriolitos) $^{(3)}$ (Figura 1). Os sinais radiológicos se caracterizam por dilatação dos canalículos superior e inferior, com ausência de dilatação do saco lacrimal e ducto nasolacrimal. Apesar de sua ocorrência rara, a canaliculite não sofre melhora espontânea, levando muitas vezes a um quadro de irritação ocular crônica e secreção ocular nos indivíduos acometidos, caso a doença não seja diagnosticada e tratada corretamente. Com o objetivo de discutir as principais formas de tratamento existentes atualmente e relatar a nossa experiência com o tratamento cirúrgico, fizemos um estudo com 7 casos atendidos no Setor de Plástica Ocular da Clínica Oftalmológica do HC - FMU SP.

MÉTODOS

Foi realizado um estudo retrospectivo com 7 casos atendidos no Setor de Plástica Ocular da Clínica Oftalmológica do HC FMUSP nos últimos 3 anos, sendo anotados os dados clínicos e as formas de tratamento adotadas para cada paciente bem como a evolução pós-operatória. 


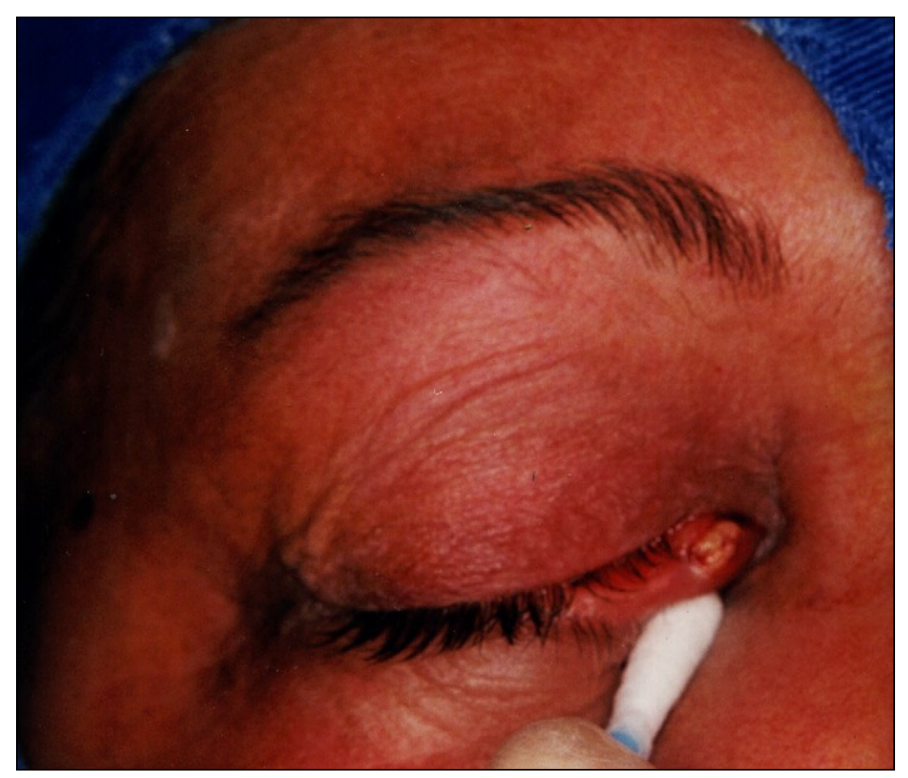

Figura 1 - Canaliculite Crônica: expressão digital do canalículo inferior com saída de dacriolitos

RESULTADOS

Os dados clínicos e a forma de tratamento encontram-se no quadro 1. Os principais sinais e sintomas encontram-se dispostos no quadro 2 .

Em nosso estudo a cultura da secreção coletada foi negativa na maioria dos casos (Streptococcus viridans).

\begin{tabular}{|ccccc|}
\hline \multicolumn{5}{c|}{ Quadro 1. Dados clínicos } \\
Paciente & Idade & Sexo & Tratamento & Evolução \\
1 & 47 & F & Canaliculotomia & Cura Completa \\
2 & 51 & F & Canaliculotomia & Cura Completa \\
3 & 69 & M & Canaliculotomia & Cura Completa \\
4 & 62 & F & Conservador & Secreção Esporádica \\
5 & 82 & M & Canaliculotomia & Cura Completa \\
6 & 73 & F & Canaliculotomia & Cura Completa \\
7 & 62 & M & Canaliculotomia & Cura Completa \\
\hline
\end{tabular}

\begin{tabular}{|cccccc|}
\hline \multicolumn{7}{c|}{ Quadro 2. Sinais e sintomas } \\
Paciente & $\begin{array}{c}\text { Conj. } \\
\text { Crônica }\end{array}$ & Epífora & Irritação & $\begin{array}{c}\text { Edema de } \\
\text { Ponto }\end{array}$ & Secreção \\
1 & + & - & - & - & + \\
2 & + & - & - & - & + \\
3 & - & + & - & + & + \\
4 & - & + & - & - & + \\
5 & + & - & - & - & + \\
6 & - & - & + & + & - \\
7 & + & - & + & - & - \\
\hline
\end{tabular}

DISCUSSÃO

O tratamento da canaliculite pode ser abordado das seguintes formas: conservador (massagem) ou cirúrgico (curetagem/canaliculotomia), variando de acordo com o cirurgião. $\mathrm{O}$ tratamento conservador, expressão mecânica do canalículo, apesar das vantagens de ser um método não invasivo, realizado apenas com massagem do canalículo e uso de antibiótico tópico, nem sempre leva à cura completa da doença e na maioria das vezes o paciente apresenta recorrência dos sintomas. Vecsei et al. relataram em sua casuística apenas uma taxa da $20 \%$ de cura completa quando o tratamento conservador foi utilizado isoladamente ${ }^{(4)}$. O tratamento cirúrgico pode ser realizado através de curetagem do canalículo ou canaliculotomia. A curetagem é realizada sob anestesia local e passagem de cureta através do ponto lacrimal dilatado ou punctoplastia. A curetagem é feita até que toda a passagem da cureta seja não produtiva. Após isso é feito o uso tópico de colírio de sulfacetamida. Estudos relatam que $45 \%$ dos pacientes apresentaram cura completa dos sintomas e sinais de canaliculite após uma única curetagem ${ }^{(5)}$. A canaliculotomia é realizada sob anestesia local, sendo feita uma incisão a partir do ponto lacrimal na extensão do canalículo, em direção ao canto medial. Após isso é feito a retirada das concreções e lavagem com antibiótico tópico, mantendo-se a ferida aberta no pósoperatório.

A etiologia mais freqüente da canaliculite é o Actinomyces israelii $^{(3)}$, porém nossos resultados diferem da literatura. A negatividade das nossas culturas talvez possa ser atribuída aos diversos tratamentos prévios com antibiótico.

É importante ressaltar que menos de um terço dos pacientes (quadro 2 - sinais e sintomas) apresentaram epífora, mostrando que esta queixa não foi tão freqüente como seria de se esperar.

Em nosso estudo apenas 1 caso foi submetido ao tratamento conservador ( 2 manobras de expressão do canalículo), havendo melhora inicial dos sinais e sintomas porém o paciente ainda apresenta atualmente discreto edema e hiperemia do ponto e secreção esporádica. Todos os pacientes submetidos a canaliculotomia mostraram cura completa dos sinais e sintomas de canaliculite crônica.

Por fim, frisamos que em pacientes com queixa de epífora e secreção crônica no ponto lacrimal devemos sempre lembrar da possibilidade de canaliculite para que seja realizado o tratamento cirúrgico adequado.

\section{ABS TRACT}

Purpose: Discuss the most important forms of treatment available nowadays and to report our experience with the surgical treatment of chronic canaliculitis. Methods: Retros- 
pective study with 7 cases assisted at the Clínica Oftalmológica of HC-FMUSP in the last 3 years. Results: All the patients submitted to surgical treatment had complete cure of the signs and symptoms. Conclusions: We should always remember the possibility of canaliculitis in patients with epiphora and chronic secretion in the lacrimal punctum so that the appropriate surgical treatment can be established.

Keywords: Eye infection, bacterial; Actinomycetales infections; Lacrimal apparatus diseases/surgery; Chronic diseases

\section{REFERENCIAS}

1. Demant E, Hurwits JJ. Canaliculitis: review of 12 cases. Can J Ophthalmol $1980 ; 15: 73-5$

2. Sullivan TJ, Hakin KN, Sathananthan N, Rose GE, Moseley IF. Chronic canaliculitis. Aust N Z J Ophthalmol 1993;21:273-4.

3. Mckellar MJ, Aburn NS. Cast-forming Actinomyces israelü canaliculitis. Aust N Z J Ophthalmol 1997;25:301-3.

4. Vecsei VP, Huber-Spitzy V, Arocker-Mettinger E, Steinkogler FJ. Canaliculitis: difficulties in diagnosis, differential diagnosis and comparison between conservative and surgical treatment. Ophthalmologica 1994;208:314-7.

5. Pavilack MA, Fruch BR. Through curettage in the treatment of chronic canaliculitis. Arch Ophthalmol 1992;110:200-2.

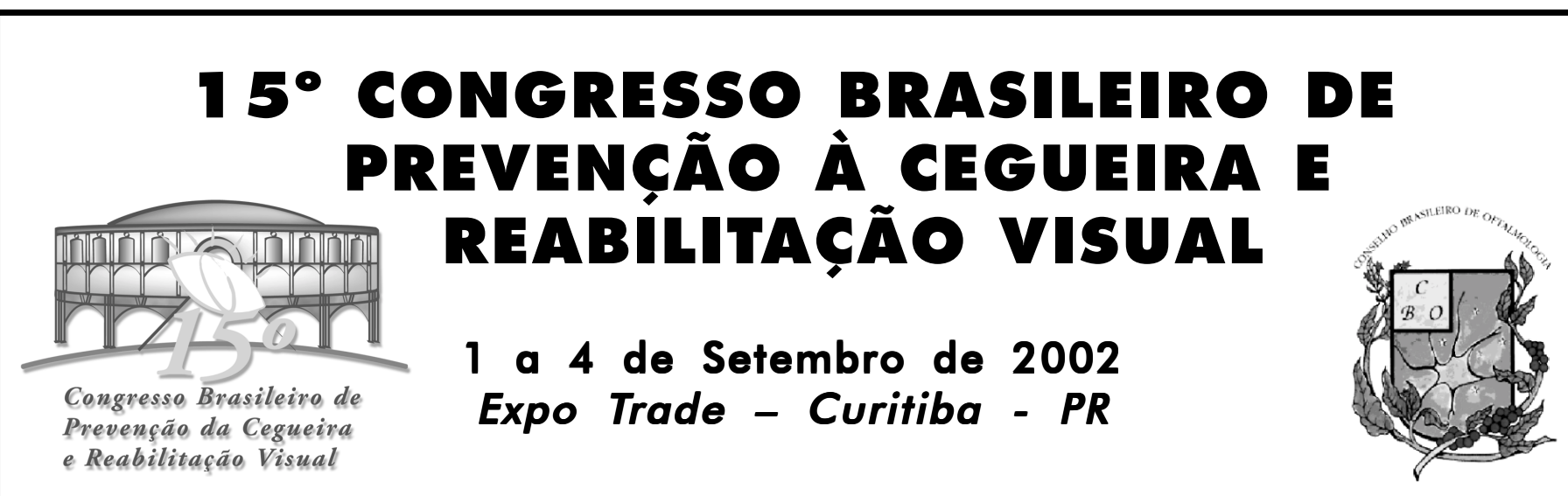

O pavilhão ExpoTrade é o segundo maior do Brasil em área coberta contínua, perfeito para receber - $15^{\circ}$ Congresso Brasileiro de Prevenção à Cegueira e Reabilitação Visual, o $2^{\circ}$ maior evento de oftalmologia do país.

Oxpo Trade está localizado em uma das mais importantes áreas da região metropolitana de Curitiba no município de Pinhais. De fácil acesso ao centro de Curitiba $(9 \mathrm{~km})$, conta com excelentes hotéis e famoso centro gastronômico, várias opções de lazer e turismo, espaços culturais, além da proximidade do litoral, através das belas paisagens da Serra do Mar.

A proximidade com importantes vias de ligação permite o deslocamento rápido ao aeroporto (8 km) ou às rodovias interestaduais.

A comissão científica está elaborando cuidadosamente a programação das atividades com especial destaque para os programas de prevenção à cegueira realizados no Brasil, a fim de promover um maior intercâmbio entre aqueles que se dedicam a esse importante tema de alcance social.

INFORMAÇÕES: Conselho Brasileiro de Oftalmologia

CBO Eventos

Tel: (1 1 ) 3266-4000 - Fax: (11) 3171-0948

Email: eventos@cbo.com.br 